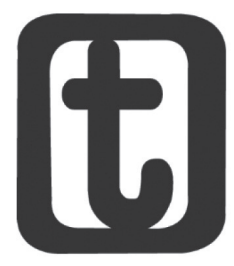

\title{
TRABALHO DE CRIANÇAS E ADOLESCENTES: DESAFIOS PARA O PROGRAMA DE ERRADICAÇÃO DO TRABALHO INFANTIL (PETI) E PARA O TRABALHO PROFISSIONAL DO SERVIÇO SOCIAL
}

\author{
CHILDREN AND ADOLESCENTS LABOR: CHALLENGES \\ FOR THE CHILD LABOR ERADICATION PROGRAM (PETI) \\ AND FOR SOCIAL SERVICE PROFESSIONAL WORK
}

\section{Edvânia Ângela de Souza Lourenço'}

\section{RESUMO}

Este texto discute os dados parciais do projeto de pesquisa e extensão universitária ${ }^{2}$, o qual busca analisar a existência do trabalho de crianças e adolescentes em Franca/SP e a efetividade dos programas sociais oferecidos. Neste texto, são analisados os dados qualitativos coletados junto às famílias atendidas pelo Programa de Erradicação do Trabalho Infantil (PETI) e aos profissionais responsáveis por este Programa no referido município. A partir desta análise, destacam-se elementos importantes para se discutir a efetividade do PETI, os desafios para o Serviço Social e a política de Assistência Social.

Palavras-chave: Programa de Erradicação do Trabalho Infantil (PETI). Sistema Único de Assistência Social (SUAS). Serviço Social. Trabalho Informal.

1 Professora do Departamento e do Programa de Pós-Graduação em Serviço Social da Faculdade de Ciências Humanas e Sociais de Franca (FCHS/UNESP) Franca/SP. É pesquisadora do Grupo de estudos e pesquisas: "Teoria Social de Marx e Serviço Social”, responsável pela linha de pesquisa: Mundo do Trabalho: Serviço Social e Saúde do Trabalhador - GEMTSSS-UNESP-Franca/SP. E-mail: edvaniaangela@hotmail.com.

2 O projeto PETI-COMPETI: uma análise intersetorial do trabalho infantil em Franca, SP. Este projeto foi devidamente aprovado pela Pró-reitoria de Extensão da UNESP, Faculdade de Ciências Humanas e Sociais (UNESP-Franca/SP), para os anos de 2011 e 2012, e pelo Comitê de Ética da UNESP- Franca, conforme Memorando CEP/Franca, n. 065/2011. 


\section{ABSTRACT}

This text discusses the partial data of the university research and extension project "PETI-COMPETI: an intersectoral analysis of child labor in Franca, SP", which intends to verify the existence of children and adolescents labor in Franca/SP and the effectiveness of social programs offered. Thus, concerning this text, qualitative data were selected referring to the families attended by the Child Labor Eradication Program (PETI) and to the professionals responsible for this Program in the referred municipality. From this analysis, important elements are highlighted in order to discuss the effectiveness of PETI, the challenges for Social Work and Social Assistance policy.

Keywords: Child Labor Eradication Program (PETI). Unified System of Social Assistance (SUAS). Social Work. Informal work.

Submetido em 16/12/2013

Aceito em 12/01/2014

\section{INTRODUÇÃO}

A submissão de crianças e adolescentes ao trabalho infantil e do adolescente situa-se como uma das expressões da questão social, cujas nódoas culturais tendem a reforçar a sua permanência ao longo dos tempos. Se por um largo período histórico o trabalho foi o centro de formação e de educação para meninos e meninas, a partir do sistema capitalista o significado educativo do labor cede lugar para o salário, tornando-se apenas uma alternativa de sobrevivência, cujo resultado é o aprofundamento da subordinação ou da subsunção do ser social ao capital e suas relações subjacentes.

Sumariamente, o trabalho precoce (de crianças e adolescentes) é uma das expressões da questão social, cujo epicentro é o modo de produção capitalista e suas subjacentes relações. Para se reproduzir e se ampliar, o capital necessita revolucionar constantemente os meios de produção, apropriando-se das inovações tecnológicas, tendo em vista o aumento da produtividade do trabalho social e a diminuição do tempo de trabalho socialmente necessário à produção de mercadorias (MARX; ENGELS, 2000). É, pois, nesse contexto que os capitalistas investem em capital constante e desprezam o capital variável, gerando desemprego e inúmeras formas de contratação e gestão da força de trabalho. Com a interrupção forçada do trabalho, coletivamente, os 
trabalhadores perdem força política para a manutenção de direitos do trabalho e sociais, outrora garantidos por meio da luta de classes: "Gera, assim, uma acumulação da miséria relativa à acumulação do capital, encontrando-se aí a raiz da produção/reprodução da questão social na sociedade capitalista" (IAMAMOTO, 2001, p. 15).

O trabalho precoce está presente em vários países do mundo. Embora não seja exclusividade dos países em desenvolvimento, nestes o problema se torna mais complexo, tendo em vista a ausência de políticas de proteção social de caráter universal. No Brasil, somente tardiamente houve o reconhecimento e o estabelecimento de leis sociais para a proteção da pessoa em fase de desenvolvimento (PADILHA, 2006).

Deve ser reconhecido que, gradualmente, vêm sendo criadas normas e regras que visam a proteção da infância, tal como o Estatuto da Criança e do Adolescente (ECA) ${ }^{3}$, entretanto a estrutura social e o modo de produção e reprodução social continuam os mesmos, ou seja, institui-se a lei, mas a realidade material, as condições de trabalho das famílias e o afastamento do Estado no exercício efetivo das políticas sociais de proteção à infância, à juventude e à família mantêm-se inoperantes. Dessa maneira, Silva (2005) destaca que, apesar de o ECA representar alguns

3 Bidarra e Oliveira (2008) fazem importante discussão acerca da legislação internacional para a proteção da infância e sua repercussão no âmbito brasileiro e dos países signatários. Os autores destacam que as discussões e a criação de leis internacionais no pós Segunda Guerra Mundial, sobretudo com a Declaração dos Direitos Humanos, em 1948, pela Organização das Nações Unidas (ONU), com a criação do Fundo das Nações Unidas para a Infância (UNICEF) e com a Declaração dos Direitos da Criança em 1959, tiveram forte influência nos países membros. No Brasil, esses fatores alimentaram os debates acerca da desatualização do Código de Menores frente à sociedade que se industrializava e se urbanizava, contudo o movimento que visava modificar o Código, seguindo as resoluções internacionais, foi empanado pelo golpe, que instaurou a ditadura militar brasileira de 1964 a 1986. "As tentativas de revisão do Código de Menores continuaram nos anos de 1970 e em meio à posição divergente destacou-se, de um lado, um grupo de juristas do Rio de Janeiro ligado à Associação de Juízes de Menores, que defendia a oficialização de um direito menorista e, de outro, o Ministério Público de São Paulo, que defendia uma legislação contemplando a garantia dos direitos dos menores. $O$ vencedor deste embate foi o primeiro grupo e em 10 de outubro de 1979 - Ano Internacional da Criança - foi promulgada a lei número 6. 697, que instituiu o novo Código de Menores. Esta legislação introduziu o conceito de "menor em situação irregular"' (BIDARRA; OLIVEIRA, 2008, p. 161). 
avanços, ele não se configura uma mudança efetiva na realidade de crianças e adolescentes.

[...] O ECA nasceu em resposta ao esgotamento histórico-jurídico e social do Código de Menores de 1979. Nesse sentido, o Estatuto é processo e resultado porque é uma construção histórica de lutas sociais dos movimentos pela infância, dos setores progressistas da sociedade política e civil brasileira, da "falência mundial" do direito e da justiça menorista, mas também é expressão das relações globais internacionais que se reconfiguravam frente ao novo padrão de gestão de acumulação flexível do capital [...] O ECA não é uma dádiva do Estado, mas uma vitória da sociedade civil, das lutas socais e reflete ganhos fundamentais [...]. Ocorre que foi uma conquista obtida tardiamente nos marcos do neoliberalismo, nos quais os direitos estão ameaçados, precarizados e reduzidos, criando um impasse na "cidadania das crianças", no sentido de tê-la conquistado formalmente, sem, no entanto, existir condições reais de ser efetivada e ser usufruída (SILVA, 2005, p. 36).

Concorda-se com Silva (2005) que o ECA ${ }^{4}$ não elimina as contradições e as desigualdades sociais em que a maioria das crianças e adolescentes brasileiros está submersa, sobretudo em tempos neoliberais. Contudo, a estrutura legal afirmada a partir da perspectiva da proteção integral da pessoa em desenvolvimento tem propiciado algumas mudanças tanto no âmbito da cultura como no campo das políticas sociais de proteção à infância55.

4 "Do ponto de vista conceitual, o Estado abandona o princípio da Infância em Situação Irregular e adota o princípio de Proteção Integral à Infância. A lógica jurídica dessa perspectiva apresenta diferenças capazes de identificar dois direitos: o direito do menor (Código de Menores) e o direito da criança (ECA). O primeiro, o princípio da doutrina da situação irregular, não atingia todos os menores, mas apenas aqueles que se identificassem com as situações descritas no art. $2^{\circ}$ do Código, sendo o menor tratado como objeto de medidas judiciais e a pobreza caracterizada como patologia social, configurando-se, assim, em lógica discriminatória, repressiva e criminalizante em relação à criança e ao adolescente pobre. O Estatuto, ao adotar a doutrina de proteção integral, rompe com essa lógica, no sentido de defender, proteger e viabilizar o desenvolvimento integral de toda a população infantojuvenil brasileira, independentemente de sua classe social" (PADILHA, 2006, p. 52).

5 Entre alguns avanços na área da infância, registra-se a diminuição da mortalidade 
Entretanto, muitos problemas ainda se mantêm no cotidiano das crianças, dos adolescentes e suas respectivas famílias. A par da exploração do trabalho estão aqueles que, às vezes, são claramente identificados, outra vezes, camuflados ou mascarados. O ECA, que não foi efetivado em sua totalidade, vem sendo alvo de questionamentos que permitem retroceder na história, como tem sido o debate acerca da inimputabilidade penal ${ }^{6}$. Quanto ao trabalho precoce, este se constitui em uma violação aos direitos resguardados para o público em foco, mas nem sempre é identificado como problema, haja vista que, diante da precariedade material das famílias e da ausência do Estado no desenvolvimento e manutenção das políticas sociais, aparece mais como uma solução.

O trabalho foi, e muitas vezes ainda é, utilizado como um poderoso instrumento para o controle social, sobretudo de crianças e adolescentes pobres, como já abordado por Padilha (2006). A autora destaca também o papel da cultura, que atribui "[...] ao trabalho precoce poderoso instrumento moral, capaz de disciplinar e, ao mesmo tempo, formar a sociabilidade das crianças e dos adolescentes" (PADILHA, 2006, p. 203). Em comunhão com esses fatores, está a precariedade do ensino público à qual a classe trabalhadora encontra-se sujeita e dependente ${ }^{7}$, o que acaba colaborando para a interrupção precoce dos estudos, uma vez que, no senso comum, quando não se vai bem na escola, justifica-se com o argumento de que é melhor abandonar os estudos e se dedicar ao trabalho .

infantil, a qual é fruto de mudanças na infraestrutura das cidades, moradias e acesso às políticas sociais públicas. "O Brasil está no rumo de alcançar o ODM 4, que trata da redução da mortalidade infantil. O país fez grandes avanços - a taxa de mortalidade infantil caiu de 47,1/1000, em 1990, para 19/1000, em 2008. Contudo, as disparidades continuam: as crianças pobres têm mais do que o dobro de chance de morrer, em comparação às ricas, e as negras, 50\% a mais, em relação às brancas" (UNICEF, 2013). Houve queda também em relação ao trabalho infantil. Considerando o período de 12 anos, de 2000 a 2012 (OIT, 2013)..

6 Esse debate tem tido uma forte presença na mídia e no Congresso Nacional, onde tramitam muitos projetos de leis que visam reduzir a maioridade para as questões relacionadas à criminalidade.

7 A política de educação vem sendo alvo de fortes questionamentos promovidos pelos recentes movimentos sociais que tomaram as ruas em junho de 2013. 
Dessa forma, o projeto PETI-COMPETI (de pesquisa e extensão) ${ }^{8}$ buscou realizar um balanço de como o PETI está sendo efetivado no município de Franca, interior do estado de São Paulo, onde o problema do trabalho precoce ainda prevalece, sobretudo no processo de trabalho da costura manual e pesponto em calçados, realizado em domicílio, como verificado em um bairro específico, durante as atividades do referido projeto (LOURENÇO, 2013). O trabalho infantil, embora esteja controlado no interior das fábricas, a partir da informalidade do trabalho, reaparece ora associado à "ajuda" às mães, no caso da costura manual de calçados realizada em domicílio, ora como forma de o adolescente se autossustentar e aprender um ofício, sobretudo, nas bancas de pespontos em calçados.

Para efeitos deste texto, foram selecionados os depoimentos parciais coletados por meio de Oficinas realizadas com as famílias beneficiárias do Programa de Erradicação do Trabalho Infantil (PETI) e com os profissionais responsáveis pelo desenvolvimento desse programa em Franca, na sua maioria assistentes sociais, trabalhadoras dos Centros de Referência em Assistência Social (CRAS), no período de 2011 e 2012, e, ainda, entrevista com uma assistente social do Centro de Referência Especializado em Assistência Social (CREAS) ${ }^{9}$. Esses dados referem-se ao modo como o PETI vem sendo desenvolvido no município, aos subjacentes desafios para o Serviço Social e à política de Assistência Social ${ }^{10}$.

8 Compreende-se que não há como separar as dimensões de formação, pesquisa e extensão, mas, infelizmente, muitas pessoas as veem de modo estanque, fato que tem levado à reprovação de projetos de extensão que não se pautam em uma abordagem articulada entre essas dimensões.

9 Neste texto, a identificação dos profissionais responsáveis pela efetivação do PETI em Franca e das respectivas unidades de trabalho foi feita de modo genérico, indicando apenas a profissão acompanhada de CRAS (A, B, C ou D). Quando se trata de familiares de crianças e adolescentes atendidas pelo PETI, são colocadas apenas as iniciais do nome e o grau de parentesco.

10 Registra-se um agradecimento especial aos membros da Comissão de Acompanhamento do PETI (COMPETI-Franca); à assistente social Lucinéia Silva Sartori Coelho, Diretora de Proteção Social Básica da Prefeitura de Franca, no período de 2011 e 2012, e às alunas bolsistas desse projeto: Aline Lima da Silva, Sheila Batista e Souza e Ana Cláudia Guiraldelli e Caroline Luise Siqueira. 


\section{O PETI EM FRANCA/SP}

As medidas de erradicação do trabalho infantil foram sendo criadas a partir de movimentos sociais e das frequentes denúncias dessa forma aviltante de exploração. Padilha (2006) afirma que o Programa de Erradicação do Trabalho Infantil foi construído em razão das denúncias de trabalho análogo à escravidão a que muitos meninos e meninas estavam submetidos nos vários Estados da Federação brasileira, sobretudo naqueles onde se sobressaía o trabalho no corte manual da cana-de-açúcar, sisal e carvoarias.

O PETI objetiva, como o próprio nome indica, erradicar, juntamente com a sociedade civil, o trabalho infantil nas atividades consideradas "perigosas, insalubres, penosas e degradantes". Conta com o repasse financeiro de uma bolsa mensal, no valor de $R \$ 25,00$, para os que residem na zona rural, e de $R \$ 40,00$ reais para os que moram na zona urbana. Além da bolsa, deve ser oferecido pelo gestor municipal o desenvolvimento de atividades socioeducativas para crianças e adolescentes no período contrário ao da escola"1.

Esse programa está contemplado na estrutura atual da política de Assistência Social e se restringe ao atendimento seletivo de crianças e adolescentes em situação de trabalho e precárias condições financeiras, com foco na eliminação das piores formas de trabalho. Portanto, este Programa atende as "[...] famílias vulnerabilizadas pela pobreza e exclusão social, com renda per capita até meio salario mínimo, com filhos na faixa etária de 7 a 14 anos..." (PADILHA, 2006, 72).

É importante registrar que a política de assistência social brasileira tem trilhado caminho de avanços e conquistas nos termos do reconhecimento da assistência social como direito ${ }^{12}$

11 A jornada ampliada deve manter perfeita sintonia com a escola. Em nenhuma hipótese, podem ser desenvolvidas atividades profissionalizantes ou ditas "semiprofissionalizantes" com as crianças e adolescentes do PETI (BRASIL, 2004, p. 7).

12 "[...] é necessário reconhecer os avanços relativos nas lutas empreendidas para que fosse possível viabilizar a Lei Orgânica da Assistência Social (LOAS), a Política Nacional de Assistência Social (PNAS) e o Sistema Único de Assistência Social (SUAS), considerando-se a perspectiva assistencialista que predominou na história brasileira marcada pelo capitalismo hipertardio e por sua forte 
e enquanto política social, portanto a sua inclusão na estrutura técnico-administrativa e política do Estado, com definições e normatizações, implica uma nova maneira de ser efetivada no país.

Destaca-se que, a partir do Sistema Único de Assistência Social (SUAS), há uma maior restrição do uso clientelista dos recursos públicos. Assim, é possível contar com algumas garantias, sobretudo recursos financeiros, já que essa política passa a contar com um fundo específico. Se a cada mudança de governo sempre existiram cortes, muitas vezes radicais no formato da política de assistência, a partir do SUAS há maior previsibilidade e continuidade das ações ${ }^{13}$.

Registra-se também que o Bolsa Família, apesar dos limites próprios de um programa de transferência de renda e do seu distanciamento das causas dos problemas que se propõe a atender, tem possibilitado um controle maior quanto à permanência da criança e do adolescente na escola, além da imunização e possível melhora na alimentação dos beneficiários. Deve-se frisar que apenas frequentar a escola não resolve o problema, uma vez que é preciso também que esta seja de qualidade.

O PETI passou a integrar o programa Bolsa Família, a partir da proposta de unificação dos programas de transferência de renda, segundo a Portaria n. 666, de 28 de dezembro de 2005 (BRASIL, 2005). Portanto, o PETI é uma política de âmbito nacional que tem como objetivo a prevenção e o combate ao trabalho infantil, estando integrado à política de Assistência Social.

Em Franca, a Secretaria de Ação Social informou que, em 2011, havia 48 famílias cadastradas no Programa de Erradicação do Trabalho Infantil, assim distribuídas: 14 famílias na região Centro;

presença repressiva e policialesca - que deixou os seus resquícios até os dias atuais - Pereira, 2000, por outro [lado], é preciso destacar funcionalidade dela para a ordem monopólica-flexível implantada em países como o Brasil" (SILVA, 2013, p. 134).

13 "Acho que ela foi um passo importante. Agora eu só entendo a legitimidade dessa assistência no marco de uma política de seguridade social [...] o que distingue o traço assistencial de qualquer forma assistencialista é que ela faz parte de uma política muito mais ampla, a política de seguridade social. Ora, isso não existe no Brasil, não existe política de seguridade social, é bastante interessante, inclusive, que a discussão acerca da seguridade social já esmaeceu [...]" (PAULO NETTO, em entrevista para SILVA, 2013, p. 137). 
10 na região Norte; nove na região Oeste; nove na região Leste; e seis na região Sul da cidade. O acompanhamento a essas famílias é realizado pelas equipes dos Centros de Referência de Assistência Social (CRAS), instalados conforme as regiões. Segundo as profissionais dos CRAS, nesses espaços, há o acompanhamento das famílias participantes do PETI e, quando há violações de direitos, como, por exemplo, crianças e adolescentes que não estão frequentando a escola ou não romperam com a prática do trabalho, o atendimento passa a ser realizado pelo Centro de Referência Especializado de Assistência Social (CREAS).

Em Franca, a origem do PETI também guarda o histórico de pesquisas que denunciaram a exploração do trabalho de crianças e adolescentes. Esse pioneirismo foi protagonizado pelo Sindicato dos Trabalhadores da Indústria de Calçados e Vestuário de Franca (STICF), que, já em 1994/1995, juntamente com o Departamento Intersindical de Estudos e Estatísticas do Trabalho (DIEESE) e a Central Única dos Trabalhadores (CUT) ${ }^{14}$, realizou importante pesquisa indicando a presença de crianças trabalhando nas fábricas de calçados do município. Essa pesquisa foi um esforço coordenado para conhecer as condições de vida e trabalho de meninos e meninas em Franca e construir possíveis alternativas ao trabalho precoce. A coleta de dados foi direcionada aos alunos da rede pública estadual, atingindo 1561 alunos, com idades entre sete e 13 anos de idade. A amostra foi composta de 35\% do total dos estudantes, dessa faixa etária, das escolas estaduais do município (OLIVEIRA, 2013). Dos alunos entrevistados, 73\% afirmaram trabaIhar na fabricação de calçados (STIC; DIEESE, 1995, p. 5).

Então, teve a Raquel Licurse, uma assistente social que atuava junto ao Sindicato dos Sapateiros e com esta pesquisa divulgou-se que havia mão de obra infantil. Essas notícias tomaram uma proporção nacional e, no caso do calçado, tomou uma proporção internacional, então tomaram proporções grandes [...] Alguns importadores, de alguns países, disseram que não importariam calçados, se houvesse mão de obra infantil na sua manufatura. Na área do calçado, houve

14 Era um projeto idealizado pela CUT, intitulado "Orientação de crianças trabalhadoras na indústria e outros setores, capacitação de sindicalistas e conscientização da sociedade" (STICF; DIEESE; CUT, 1995). 
a criação do Instituto Pró Criança. Criou-se o Instituto para oferecer alternativas para os filhos dos trabalhadores e criar um mecanismo de fiscalização para as empresas não usarem mão de obra infantil, porque houve retaliação (Assistente Social do CREAS).

A dimensão da denúncia do trabalho infantil, a partir da referida pesquisa, e sua divulgação adquiriram grandes proporções, uma vez que a questão se relacionava diretamente com a economia do município. Assim, alguns países, para onde era exportado o calçado francano, como, por exemplo, os Estados Unidos da América (EUA), ameaçaram rescindir os contratos, caso fosse comprovado o uso do trabalho infantil no processo produtivo do sapato e, nesse sentido, os EUA enviaram representantes a Franca, que ratificaram os dados da pesquisa feita pelo STICF (mais conhecido como Sindicato dos Sapateiros).

Segundo Oliveira (2013), somou-se às denúncias e apurações externas uma Ação Civil Pública da Procuradoria Regional do Trabalho de Campinas, imputando o pagamento de multas às empresas que continuassem contratando as bancas de pespontos que utilizavam o trabalho infantil. Tudo isso pressionou os empresários a assinarem um acordo para a eliminação do trabalho precoce, em 1997, como divulgado pelo jornal Folha de S.Paulo, em reportagem publicada em 04 de dezembro de 1997, citada por Oliveira (2013).

Dessa maneira, o setor patronal criou o Instituto Pró Criança, como afirmado pela assistente social entrevistada. Esse Instituto passou a desenvolver algumas ações para eliminar o uso da força de trabalho infantil em Franca. Também foi implantado o Programa Renda Mínima por parte do governo do Estado e do município, para atender os casos de trabalho infantil.

Nos anos 2000, outra pesquisa também denunciou o trabalho infantil em Franca, dessa vez em um lixão da cidade, “[...] quem foi a coordenadora da pesquisa foi uma Assistente Social de nome Fátima, que trabalhava na Secretaria de Assistência Social (Assistente Social do CREAS).

Observa-se que a pesquisa realizada no lixão da cidade também ganhou proporções maiores porque os dados desse 
estudo foram encaminhados ao governo federal: "[...] e o Brasil já estava implantando um trabalho de erradicação do trabalho infantil e Franca foi contemplada, na época, com 150 vagas para a gente incluir prioritariamente essas famílias..." (Assistente Social do (REAS).

Paralelamente ao encaminhamento do resultado da pesquisa ao governo federal e à ampliação do Renda Mínima em Franca para atender as famílias que tinham filhos trabalhando no referido lixão, o governo municipal também removeu o lixão para outro lugar, mais afastado, a partir de uma estrutura mais adequada, a fim de evitar que as famílias e seus filhos retirassem do lixo o seu sustento.

Há de se fazer um destaque para a realização dessas pesquisas, as quais contaram com apoio e participação de duas assistentes sociais, uma vinculada ao Sindicato dos Sapateiros e a outra à Secretaria Municipal de Ação Social de Franca.

A pesquisa tem um papel fundamental para compreender as demandas postas tanto no cotidiano do movimento sindical quanto na formação e trabalho profissional do Serviço Social, sendo possível, a partir dos seus resultados, criar intervenções mais qualificadas. É uma forma de evitar a ação puramente pragmática. Portanto, no cotidiano profissional do Serviço Social, é preciso desenvolver estudos com rigor científico e adensamento teórico - a partir dos postulados teórico-metodológicos defendidos pela categoria profissional e respectivo Projeto Ético-Político - a respeito das demandas dos serviços.

Daí a necessidade de formar profissionais capazes de desvendar as dimensões constitutivas da chamada questão social, do padrão de intervenção social do Estado nas expressões da questão social, do significado e funcionalidade das ações instrumentais a este padrão, através da pesquisa, a fim de identificar e construir estratégias que venham a orientar e instrumentalizar a ação profissional, permitindo não apenas o atendimento das demandas imediatas e/ou consolidadas, mas sua reconstrução crítica (GUERRA, 2009, p. 702). 
Esse movimento de pesquisa e denúncia do trabalho infantil em Franca exigiu determinadas respostas dos órgãos de governo e empresariado, que atenderam parcialmente à demanda. Tal modo de implantar políticas sociais se vincula a uma forma paliativa de tratar os problemas sociais. Diante das denúncias de determinado fenômeno, o Estado e os representantes da sociedade civil, incluindo empresários, buscam oferecer respostas, em geral, de modo paliativo, por exemplo, no caso do trabalho infantil, não se trata de construir políticas universais voltadas para a infância e adolescência, mas de atender apenas aquelas que estão envolvidas em situações de trabalho. Ou seja, como esse modo de produção está assentado nas relações desiguais e se infla em face da exploração do trabalho, não se prevê uma redistribuição da renda, no sentido de garantir condições de vida seguras e igualitárias. Ao contrário, a renda da produção é apropriada pelos donos dos meios de produção, restando aos trabalhadores, detentores da força de trabalho, quando empregados, apenas o salário, via de regra, muito abaixo das necessidades de consumo e de acesso aos principais bens.

Ao longo dos tempos, as medidas de proteção social têm sido criadas a partir das lutas sociais e, sobretudo, quando estas ameaçam a economia política. Ou seja, no momento em que o problema ganha proporção e reprovação da sociedade, o Estado é pressionado a regular e normatizar a respeito de determinado assunto, instituindo medidas paliativas, tais como o Renda Mínima, o Bolsa Escola e, entre outros, o PETI e o Bolsa Família, que, apesar da sua importância, no contexto atual, não conseguem modificar a realidade dessas famílias ${ }^{15}$.

15 Silva (2013) realiza importante discussão acerca da política de Assistência Social, sendo oportuno reproduzir o trecho da entrevista que o autor fez com a Profa. Ozanira Silva e Silva: "A Política de Assistência Social não é direcionada só para quem não trabalha, mas é para quem trabalha e quem também tem essa condição de precariedade. Isso, inclusive, foi lembrado na nossa mesa de debates feita ontem: os próprios beneficiários do Programa Bolsa Família, por exemplo, mais de 70\% (setenta) trabalham. Mas, que tipo de trabalho? Qual é o trabalho que eles ganham? Claro que é um trabalho precário, com baixos salários. [...] A Política de Assistência Social, na minha leitura, não está contribuindo para as pessoas não terem acesso ao trabalho, mas ela é funcional neste momento do capitalismo, em que o trabalho precário e instável se amplia. Então, ela é requisitada considerando a própria situação estrutural. [...] Agora, nós assistentes sociais, que historicamente temos uma vinculação com a Política 
Observa-se que o fato de o trabalho infantil ter sido identificado no lixão criou uma comoção social, em geral, não verificada em outros contextos de trabalho:

\begin{abstract}
[...] todo mundo concordava que era um serviço degradante, que era um serviço perigoso, atingia diretamente o desenvolvimento infantil, ficava no sol mexendo no lixo, era uma coisa que chocava. Então, todos eram de acordo... tem que tomar uma providência, é diferente de outro tipo, por exemplo, se perguntar se tem um menino carregando caixa pesada em um varejão aí... vai falar não, mas o menino está lá, está trabalhando... melhor estar lá trabalhando do que estar na rua, porque é como se houvesse apenas uma alternativa, ou é a rua ou é o trabalho, né!? (Assistente Social do CREAS).
\end{abstract}

A assistente social chama a atenção para a comoção social que o trabalho de crianças em um lixão pode causar na sociedade. Isso ocorre, talvez, por este se configurar como um trabalho penoso e degradante, uma vez que, nesse ambiente, não há qualquer proteção. Assim, crianças, adolescentes e familiares ficam expostos às intempéries, à condição de insalubridade do espaço e ao contato com os mais variados objetos e substâncias, portanto, submetidos à incidência de doenças respiratórias, dermatológicas e digestivas, sendo comum também a ocorrência de acidentes provocados por materiais cortantes, pontiagudos, entre outros. Além desses aspectos, há o fato de esse problema ser visivelmente constatado. Já quando o trabalho acontece em um supermercado, ou em um varejão, torna-se visível e invisível ao mesmo tempo: visível porque está à vista de todos, não está escondido nas relações privadas, como é o caso do trabalho

de Assistência Social, então agora tem um grupo dizendo: 'era bom não ter a Política de Assistência Social, no sei o quê...'. Eu que faço pesquisa empírica, eu sugiro, por exemplo, que as pessoas façam pesquisa empírica e perguntem para o beneficiário do programa Bolsa Família o que esse programa significa para eles. A partir daí vamos ver se teremos a coragem de dizer que o programa não deve existir. Eu posso dizer que o programa é funcional à pobreza. E eu digo isso em todos os textos que eu produzo sobre o tema. O Programa Bolsa Família, seguramente, não vai acabar com a pobreza. Ele esta controlando a pobreza, mantendo a pobreza num dado padrão de controle. Ele serve para legitimar o poder político, mas também atenua a situação de miséria de milhões de famílias [...]" (SILVA; SILVA em entrevista para SILVA, 2013, p. 140-141). 
precoce nas bancas de calçados e da costura manual de calçados, como já discutido (LOURENÇO, 2013). Nesses ambientes, o trabalho ocorre na esfera privada e reifica-se cotidianamente por meio das relações laborais que se misturam às afetivas, ao lar e às demandas do dia a dia, sendo, portanto, muito mais difícil de ser visto ou denunciado. No caso do supermercado ou varejão, há também uma grande dificuldade de romper com o trabalho do adolescente, uma vez que está tão naturalizado que não gera uma comoção capaz de reverter essa situação. Há o entendimento de que é melhor estar trabalhando do que ficar na rua. O trabalho em um varejão ou supermercado pode submeter os precoces trabalhadores ao excesso de peso, ao trabalho noturno, mas ninguém denuncia isso.

[...] No lixo ninguém é de acordo, é diferente de você falar: ah, o menino está ajudando o pai a costurar sapato, melhor estar dentro de casa costurando o sapato do que estar na rua fazendo o que não presta, [inclusive] as Assistentes Sociais também, muitos profissionais da nossa área pensam assim, eu acredito assim, é mais fácil você ter esse discurso do que dizer deveria ter outras oportunidades, poderia estar fazendo curso de inglês... um esporte... (Assistente Social do CREAS).

Historicamente, as interpretações do senso comum e também de vários profissionais, o que não isenta o Serviço Social, acabaram sedimentando a ideia de que a criança ou o adolescente, ao "ajudar" a família na faina ou labor diário (entende-se trabaIhar), e ao realizar atividades remuneradas, encontra-se melhor do que quando ocupa o tempo com o que aparentemente não tem retorno para os filhos da classe trabalhadora.

Essa representação também foi afirmada pelas famílias atendidas pelo PETI (LOURENÇO, 2013). Ou seja, no geral, se o trabalho precoce mostra-se mais cansativo e exige maior esforço físico, ou ainda se for pesado ou sujo, como é o caso do lixo, terá maior compromisso da sociedade para a sua eliminação, assim como ocorreu com o trabalho de meninos e meninas no corte de cana-de-açúcar. Porém, por outro lado, quando se trata de adolescentes e de atividades consideradas “leves" e limpas, como é o caso das bancas de pespontos e do corte em calçados, bem como 
do trabalho em casa, da costura manual de calçados, do comércio e do trabalho doméstico, entre outros, o trabalho não é visto como algo penoso, portanto, não incita reações contrárias majoritárias e capazes de eliminá-lo.

$\mathrm{Na}$ realidade, existe na sociedade um forte valor cultural que considera o trabalho como o principal meio para a disciplina e recurso pedagógico para os filhos das classes menos favorecidas. O trabalho aparece como modo para a preparação da vida adulta, entretanto a sua iniciação precoce tende a perpetuar aquelas atividades desvalorizadas e mal remuneradas.

Dessa maneira, o trabalho infantil em Franca foi constatado, por meio das pesquisas já referidas, nestas duas áreas: setor calçadista e lixão, sendo que nesse último caso o problema foi eliminado. No entanto, no que concerne ao setor calçadista, o avanço da terceirização, o trabalho em bancas de pespontos e a costura de sapatos em domicílio acabaram por proporcionar a continuidade do trabalho precoce, porém com maiores dificuldades de identificar a sua localização, conforme discutido anteriormente por Lourenço (2013) e citado pela assistente social: "[...] a fiscalização está nas fábricas, né? Então, o menor não vai estar lá, ele vai estar nas Bancas, a fábrica vai ter o selo. É nas Bancas que ficam escondidas e que está este problema" (Assistente Social do (RAS-D).

\section{A EFETIVIDADE DO PETI EM FRANCA/SP: LIMITES E DESAFIOS}

A partir dos anos 1990, têm sido disseminadas as medidas neoliberais de governo, cujas mudanças vão além do significado econômico. A orientação é que a rigidez das relações sociais de trabalho deve ser substituída pelos contratos mais flexíveis, com menos custos trabalhistas, reduzindo e, por vezes, eliminando as garantias e os direitos do trabalho (SADER; GENTILI, 1995). Em termos políticos, o Estado passa a ser visto como atrasado, ultrapassado e, para se modernizar, realiza inúmeras reformas que favorecem o capital, tanto por reduzir os controles fiscais, possibilitando maior liberalização da movimentação da economia e integração entre mercados, principalmente o financeiro, através de câmbio, ações e créditos, quanto pela desregulamentação do trabalho (SADER; GENTILI, 1995). Apesar da garantia 
de direitos que reza a Constituição Federal de 1988, a partir da contrarreforma do Estado, dissemina-se o padrão mais seletivo e focalizado das políticas sociais, dificultando o acesso aos direitos sociais e estabelecendo uma rota de colisão entre o que está na lei e o que existe de fato. Tal situação repercute no modus operandi das várias políticas sociais, as quais vão se tornando áreas estratégicas da gestão capitalista (MOTA, 2009).

Assim, ao se analisar o PETI, em Franca, chama-se a atenção para a focalização, para os baixos valores pagos pela bolsa e para a descontinuidade das ações socioeducativas que deveriam ser desenvolvidas pelo Programa. "Outra modalidade de atendimento é a Jornada Ampliada ${ }^{16}$, que consiste no oferecimento de ações socioeducativas para as crianças/adolescentes, em horário complementar ao da escola, tipo recreação, reforço escolar, artes, músicas, esportes e complementação alimentar..." (PADILHA, 2006, p. 74).

Durante as Oficinas com as famílias beneficiarias do PETI foi sublinhada a necessidade de ter ações socioeducativas no período contrário ao da escola, diariamente e nos vários bairros, de forma igualitária. A sua ausência é uma porta aberta para o trabaIho precoce, entre outros problemas, tais como: evasão escolar, marginalidade, drogadição. A heterogeneidade das atividades oferecidas também foi uma questão bastante pontuada pelas famílias, já que pode ocorrer a identificação da criança ou do adolescente com o que é oferecido em outro bairro, mas, em geral, eles não podem participar, devido aos critérios de território ou porque fica difícil a sua locomoção até o local da atividade.

As famílias beneficiárias do PETI destacaram a ausência ou as frequentes interrupções das atividades socioeducativas, bem como os baixos valores pagos pelas bolsas, como os principais desafios a serem enfrentados.

16 "Para financiamento das atividades da Jornada Ampliada, o Governo Federal repassa, mensalmente, através do Fundo Nacional de Assistência Social, diretamente aos municípios, valor mensal correspondente a $\mathrm{R} \$ 20,00$ por criança/adolescente da zona rural e $\mathrm{R} \$ 10,00$ por criança/adolescente da zona urbana" (PADILHA, 2006, p. 74). 
Sabe do que eu sinto falta? É do meu filho participar, como ele vinha participando, é que acabou, não tá mais indo, fazendo atividade... então, o PETI é bom, sim; pra quem recebe esse dinheirinho já ajuda, mas se tivesse fazendo atividade era melhor ainda. Porque eu trabalho... o dia inteiro... Às vezes, eu chego, ele tá na rua, não tem nada pra fazer... Eu sinto falta disso... (M. Mãe beneficiária do PETI).

As famílias afirmaram que, em 2010, ainda eram oferecidas aos participantes do PETI atividades socioeducativas no horário contrário ao da escola, tais como: coral, natação, futebol, entre outras, mas que foram interrompidas no final do referido ano, sendo que no final de 2012 ainda não haviam sido retomadas. Para as famílias, essas atividades ofereciam maior segurança, tendo em vista que os filhos aprendiam alguma coisa, não ficavam na rua e, assim, os pais podiam trabalhar com mais tranquilidade, garantindo a infância livre de trabalho.

Então, a gente tinha, nessa época, as atividades na comunidade, na $A B B$, que chamava $A B B$, comunidade pertencendo ao PETI, e um controle da frequência escolar, uma ação com as escolas, para a gente conversar a respeito, para identificar o trabalho infantil, fazer o acompanhamento com a equipe (Assistente Social do (RAS-A).

A assistente social confirma que, de fato, as atividades socioeducativas estavam interrompidas. Ela também registra que anteriormente eram realizadas atividades em um clube da cidade $(A B B)$ com os beneficiários do PETI, além do controle da frequência escolar e do acompanhamento dos casos de trabalho precoce.

A frequência das crianças e dos adolescentes nas instituições escolares necessita estar articulada ao desenvolvimento de atividades extras que ofereçam oportunidades de os estudantes ampliarem os seus conhecimentos e, sobretudo, de terem apoio e estímulo aos estudos. Os entrevistados disseram que havia, em Franca, aulas de dança e natação para os beneficiários do PETI. Esse tipo de atividade estimula a frequência e o gosto pela escola. Observa-se que existe uma carga horária que as crianças e os adolescentes vinculados ao Programa têm que cumprir, o que não vem sendo respeitado. 
Alguns dos projetos realizados pelo PETI contavam com profissionais, como pedagogos e professores de educação física, que ofereciam apoio aos participantes:

[...] eu achava muito bom..., às vezes, em casa acontecia algumas brigas, sabe? daí chegava lá, eles conversava com a gente..., aconselhava ajudando a gente, sabe? Então, eu achava isso muito bom, agora, faz muita falta o PETI pra gente..., faz um tempo que não tá tendo mais. Eu já fui no CRAS, várias vezes, procurar, mas não tá tendo, aí eu acho que faz falta porque, igual meu irmão, eu também tenho o de 12 anos, ele não para em casa, fica só na rua, quando ele tava no PETI, ele ia pro PETI ou pra escola e tinha um comportamento diferente, agora, ele tá assim muito rebelde, aí como minha mãe trabaia... (L. Adolescente beneficiária do PETI).

Chama a atenção a preocupação da entrevistada de 14 anos de idade com o seu irmão de 12 anos. Ela diz que, devido às atividades do PETI, em Franca, terem sido interrompidas, o seu irmão acaba ficando na rua e tem apresentado um comportamento mais rebelde. Alguns dos projetos que desenvolviam atividades socioeducativas contavam com profissionais que acolhiam esses meninos e meninas, dialogando acerca de inúmeras questões, portanto, contribuíam para o seu desenvolvimento social e emocional.

As atividades socioeducativas desenvolvidas por profissionais especializados têm um relevante significado social, pois são possibilidades de incorporação de referências, comportamentos e atitudes para o público infantil e adolescente. Esses profissionais, muitas vezes, adquirem um papel norteador, esclarecedor e até mesmo um modelo/referência mais duradouro para a pessoa em desenvolvimento. Dessa maneira, acredita-se que as atividades socioeducativas ${ }^{17}$ se configuram em importantes estratégias para o atendimento do público em foco, uma vez que, estando

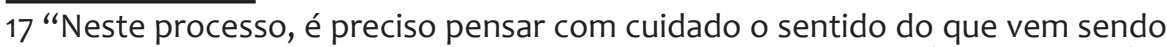
denominado como socioeducativo, seja para negar a redução dele a ações pontuais, 'inclusivas' ou de forte apelo psicossocial centrado em dinâmicas unicamente individuais, ou, ao contrário, seja para atribuir ao Serviço Social um papel que ele, por si só, não pode viabilizar: a consciência das massas e a emancipação humana" (SILVA, 2013, p. 189). 
em formação, estão conhecendo as regras, normas sociais e, dentre outros fatores, construindo as suas identidades. Além disso, participar de atividades esportivas ou recreativas contribui para a adesão escolar, lembrando que muitos meninos e meninas nunca entraram em uma sala de cinema, clube etc., o que supõe que tais atividades podem facilitar o acesso à cultura e ao lazer.

As famílias atendidas pelo PETI foram unânimes em destacar a falta que as atividades socioeducativas ofertadas pelo programa estavam fazendo no seu cotidiano. Uma adolescente relembrou um dia de lazer com a mãe, em um clube, durante uma atividade do PETI: "[...] eu fui pra Ribeirão Preto, nós foi no clube, assim, junto com as mães, isso foi o melhor..." (B. Adolescente beneficiária do PETI).

[...] minha irmã... quando ela começou no PETI... antes a pessoa é revoltada porque fica dentro de casa e, depois que ela começou o PETI, ela deu uma mudada... então, acontece assim, ela deu uma mudada radical, aí, depois que aconteceu assim, que a minha mãe faleceu, ela foi dando uma recaída... aí a única coisa que ela queria era voltar pro PETI, porque eu acho, assim, no PETI dá uma disposição pra ela, porque se a psicóloga lá dentro conversa, é melhor do que ela fazia com a outra psicóloga... (G. Beneficiário do PETI).

Ah, o PETI ajuda né, quando eu ia nem ficava mal, ia de manhã pra escola e de tarde pro PETI, de noite chegava e ficava assistindo TV e dormia..., agora eu estudo de manhã e só fico na rua, lavo as louças e saio pra rua, com o PETI não... (A. Adolescente beneficiário do PETI).

Os depoimentos expressam as injunções que a interrupção das atividades socioeducativas oferecidas pelo PETI têm causado na vida dos beneficiários e familiares. É importante que os profissionais responsáveis pelo PETI observem a diversidade das realidades atendidas, a fim de que, a partir de uma análise ampliada, possam propor ações que estimulem a família e a sociedade a conjugarem esforços para a erradicação do trabalho infantil, construindo assim iniciativas inovadoras de proteção social às crianças e aos adolescentes. É mister que os profissionais estejam 
em processo de educação permanente, indo além dos espaços de planejamento e avaliação do trabalho profissional.

Deve ser pontuado que a política social brasileira se apresenta segmentada não apenas por fragmentos da população (criança, jovem, idoso, deficiente etc.), mas também segundo os problemas manifestados, institucionalizando as medidas para quem está em situação de rua, trabalho precoce, drogadição, abandono, entre outros exemplos. Assim, em Franca, pode-se dizer que não se efetivou concretamente a necessária organização de uma política de proteção universal à infância e à adolescência, e muitos projetos, apesar da sua importância, apresentam-se mais como um papel simbólico do que realmente um meio efetivo de atender a demanda que pretende responder. Tal maneira de desenvolver políticas sociais no Brasil tem mantido as atividades de lazer, cultura e esporte adstritas a raros projetos sociais, apesar do reconhecimento destas enquanto medidas fundamentais na formação e bem-estar de crianças e adolescentes, cujo potencial está também em dissociar o público infantojuvenil da marginalidade e em oferecer bases de apoio mais rigorosas ao sistema de educação.

Mas ela mudou muito depois que ela fez o PETI... Desenvolveu, cresceu... A ideia dela é completamente diferente depois que ela fez o curso. Melhorou cem por cento... (V. Mãe beneficiária do PETI).

Eu participei do Filadélfia [como era?] Um negócio que nós reunia e fazia muitas coisas..., foi lá no Brasilândia [bairro], antes era até os 16 anos, depois veio pros 15, aí era só até os 14 anos... (A. Adolescente beneficiário do PETI).

A descontinuidade dessas atividades vincula-se aos cortes de gastos, conforme proposto pelo projeto neoliberal de governo. Como apontado por um beneficiário, já vinham ocorrendo algumas restrições à participação, como a redução da idade, que passou de 16 para 14 anos.

As dificuldades vivenciadas pelos beneficiários do PETI quanto à ausência das atividades socioeducativas ampliam-se 
em decorrência do baixo valor repassado pelo Programa por beneficiado ${ }^{18}$.

[...] meu menino também precisa comprar um tênis, esse dinheiro do PETI não dá... (M. Mãe beneficiária do PETI).

É, esse valor é muito pouco, né?, porque é mais fácil a gente trabaiar e receber o salário do que receber só $R \$ 40,00$ reais do PETI (L. Adolescente beneficiária do PETI).

É, R\$40,00 real tá baixo, né?, dá pra trabalhar pra ganhar $R \$ 600,00$. Eu trabalhava no mercado [o que você fazia no mercado?] Fazia de tudo menos açougue e caixa... É reposição, pacote, então tudo. [Qual era o seu horário de trabalho?]: De tarde, das 13h às 20h. [Você achava cansativo?] Não é cansativo, porque é muito ruim, é de frente de casa fico vendo os moleques andando pra lá e pra cá e eu fico lá... (A. Adolescente beneficiário do PETI).

$\mathrm{O}$ tom do discurso demonstra que o valor recebido pela bolsa do PETI é ínfimo, mesmo assim as famílias sentem-se agradecidas, uma vez que esse recurso significa uma ajuda. Padilha (2006), em seu estudo, mostra que a renda advinda do PETI se constituía em maior fonte de renda da maioria das famílias desse Programa em Pernambuco, a qual aparece combinada à renda de trabalhos eventuais, temporários, por conta própria, tendo em vista que essas famílias estão premidas pelas condições de baixa qualificação profissional e pelo desemprego.

\section{O PETI E OS DESAFIOS PARA A POLÍTICA DE ASSISTÊNCIA SOCIAL}

Como já destacado, o PETI integra a política de Assistência Social do município e sofre com os problemas tradicionais vivenciados pelas políticas sociais públicas, como a carência de ações

18 "O Programa prioriza as mães como responsáveis preferenciais no recebimento da bolsa. Somente na ausência da mãe por morte, separação ou abandono, ou ainda, nos casos de incapacidade física ou mental para gerir os recursos da bolsa é que outras pessoas, dentre elas o pai, os avós ou tias, assumem tais responsabilidades. A escolha da mulher/mãe deve-se ao fato de que ela proporciona o controle mais sistemático da forma como vai ser gasto o dinheiro do benefício" (PADILHA, 2006, p. 97). 
mais integradas e intersetoriais, portanto o insulamento desse Programa a uma única política também é um limite a ser enfrentado. Assim, além das dificuldades já indicadas, devem ser considerados os limites postos pelo modo como as políticas sociais vêm sendo geridas, sobretudo de assistência social, que sofre também com a falta ou insuficiência de recursos humanos e financeiros. Embora a atual configuração da política de Assistência Social signifique avanço em relação à maneira tradicional de desenvolver as ações que lhe dizem respeito, ainda existem inúmeros problemas no dia a dia dos CRAS e dos CREAS. Um exemplo é o tamanho das equipes desses serviços, as quais são, na realidade, miúdas, não contando, em geral, com educadores, necessários, sobretudo, para o trabalho com crianças e adolescentes. Além disso, com a equipe reduzida, o acompanhamento às famílias e às várias especificidades presentes no dia a dia acaba fragilizando a atuação profissional do assistente social.

Diante da demanda e do acúmulo de trabalho, as assistentes sociais não encontram tempo para planejar e avaliar as ações, o que reflete na qualidade da ação. Essa situação de trabalho repercute também na saúde desses profissionais, que podem inclusive adoecer, em decorrência da sensação de estar só, da falta de reconhecimento e de visualização dos resultados do seu trabalho e, ainda, por conviver diariamente e de modo isolado (haja vista a fragmentação das várias políticas) com uma gama imensa de problemas sociais de grande parte da população, não detendo os meios de resolvê-los.

Durante as Oficinas com os profissionais responsáveis pelo PETI, as assistentes sociais apresentaram alguns problemas presentes no seu cotidiano de trabalho. São funcionários públicos, mas que, na maioria das vezes, acabam não tendo um plano de carreira e, assim, não têm motivação para a educação continuada. As várias capacitações oferecidas pela Secretaria visam atender às necessidades pragmáticas dos diversos Programas e respectivas mudanças introduzidas pelo SUAS ${ }^{19}$. Somam-se a isso as

19 A partir da implantação do Sistema Único de Assistência Social (SUAS), os serviços públicos, as Organizações Sociais (OS), as Organizações Não Governamentais (ONG) e demais instituições que estão envolvidas com essa política têm promovido inúmeros cursos de preparação profissional para 
atuais contradições que permeiam as contratações no âmbito do Estado; dessa forma, muitos contratos de assistentes sociais se dão por projetos, por tempo determinado, mediante instituições terceirizadas, o que reflete no exercício profissional e na redução da sua ação às atividades iminentemente práticas.

Dessa maneira, acabam conformando um tipo de atuação, cuja organização e efetivação do trabalho estão centradas, na maior parte das vezes, no sistema de plantão, restando pouco tempo para as ações socioeducativas ou de grupos e, ainda, para a qualificação profissional, que deve ser continuada. “[...] é, porque em uma outra reunião [referência às Oficinas] acho que a gente tava muito sem perspectiva, sabe? Muito acomodado, tanto a gente como as famílias, porque as famílias têm dificuldade para expandir e a gente também tem" (Assistente Social do CRAS-D).

Assim, o trabalho profissional do Serviço Social passa a se situar na contracorrente do que a categoria vem, ao longo dos tempos, construindo como referência, conforme afirma Sant'Ana (2009, p. 156): “[...] o profissional pode trabalhar assuntos que permitam desvendar os complexos mecanismos que garantem à ideologia dominante espraiar-se por todos os interstícios da vida". Contudo, diante das precárias condições de trabalho, aumento da demanda e ausência de um olhar mais crítico sobre a realidade, o assistente social acaba retornando "[...] as propostas pedagógicas que servem ao controle e à despolitização das relações sociais" (SANT'ANA, 2009, p. 156).

As atividades relacionadas ao PETI têm especificidades que se referem ao trabalho com crianças e adolescentes. Dessa forma, o planejamento das ações devem considerar os interesses dos beneficiados, para que sejam incentivadas a interrupção do trabalho e a frequência escolar.

efetivação do SUAS, no entanto esses cursos têm sido caracterizados mais como uma capacitação técnica. A "formação profissional”, aqui reduzida à capacitação setorizada, também é banalizada por um processo que prioriza a assimilação acrítica da lei, da política e de suas normas operativas, que, devidamente ruminadas, devem servir de base para uma requalificação que gerencie o sistema social, evite transtornos patológicos que impeçam o seu adequado funcionamento e promova a "cidadania inclusiva" (SILVA, 2013, p. 131). 
Destaca-se a necessidade de oferecer atividades que sejam atrativas e que não se refiram apenas à ajuda financeira ou se restrinjam a um suposto local para atender ao público infantojuvenil. É preciso conseguir o envolvimento dos beneficiários e suas respectivas famílias, o que supõe o desenvolvimento de atividades do seu interesse. Esse é um importante desafio, tendo em vista que a equipe responsável pelo PETI deveria contar com autonomia profissional na escolha e desenvolvimento das atividades, as quais, na realidade, acabam sendo definidas pela administração da Prefeitura e pela equipe gestora da Secretaria de Ação Social, da qual a política de Assistência Social do município faz parte.

A assistente social explica que, no momento (final de 2012), o PETI estava oferecendo um curso aos beneficiários: “É de informática. Só que não é informática básica, inicia pela básica e depois aprende até a montar e desmontar computador, então assim, é bem mais completo" (Assistente Social do CRAS-B). Sobre a dinâmica do curso, ela explica: "São três horas de curso, três vezes na semana..., três dias à tarde pra quem estuda de manhã e três dias de manhã pra quem estuda de tarde... com passe de ônibus e com o lanche" (Assistente Social do CRAS-B).

Observa-se que a Prefeitura comprou o referido curso do SENAC para oferecer aos adolescentes do PETI. "[...] Então, compramos 25 vagas para o período da manhã e 25 vagas para o período da tarde. Isso pro CRAS X é muito, eu tenho cinco... acho que quatro só, da minha região, porque o restante não quis, porque eu fiz a visita, porque o meu contato é direto com adolescente" (Assistente Social do CRAS-B). Esse curso não poderia se configurar como atividade socioeducativa, tendo em vista que está voltado à formação profissional dos adolescentes. Trata-se de uma importante iniciativa, contudo não pode substituir as atividades - Jornada Ampliada - propostas pelo PETI, as quais precisam ser regulares e os beneficiários do Programa deveriam estar realizando-as nos seus próprios bairros, no horário contrário ao da escola, sistematicamente.

O tipo de curso que foi oferecido, no caso informática, fragmenta e individualiza os interesses e os beneficiários, uma vez que estabelece o atendimento de alguns quesitos que os beneficiários 
do PETI podem não conseguir atender. A consequência é que o referido curso acaba não conseguindo contemplar a demanda desse programa. Outra prerrogativa é o reforço ao aspecto laboral. Segundo Padilha (2006), existe um conjunto de contradições que perpassam o PETI, porque, por um lado, propõe-se a erradicar o trabalho de crianças e adolescentes e, por outro lado, nas entrelinhas das propostas educacionais, está - latente e explícito - o incentivo às atividades voltadas à formação de habilidades e ofícios que contribuem para enfatizar mais a cultura da educação para o trabalho do que propriamente a erradicação do trabalho precoce (PADILHA, 2006).

Sem proceder a uma interação maior com as famílias beneficiárias do PETI, o número de vagas para o curso de informática comprado pela Prefeitura aparece como superior à demanda. Como a profissional disse, ela teria apenas cinco, quatro ou três adolescentes: [...] "você conversa com o adolescente, faz o convencimento, mas ele fala que não quer, e eu não tenho como obrigar, porque, se eu obrigar, ele não vai, e, aí, essas vagas que sobraram a gente passou para a comunidade" (Assistente Social do CRAS-B).

Paradoxalmente, a maior dificuldade enfrentada pelas famílias em relação ao PETI refere-se às atividades socioeducativas, como já frisado, contudo não se trata somente de fazer reuniões com os familiares para orientações mais gerais, isso deve ocorrer, de modo planejado, inclusive com as famílias. Porém, as dificuldades que as famílias beneficiárias do PETI relataram relacionam-se à ausência de atividades coordenadas e sistemáticas para os meninos e meninas em horários contrários ao da escola, além de terem indicado também os baixos valores proporcionados pelas bolsas. Portanto, a informação de que os adolescentes não quiseram fazer tal curso deve ser vista com mais vagar e atenção.

O caráter de inoperância do PETI vincula-se ao modo como este vem sendo realizado e à ausência de um orçamento federal, estadual e municipal que garanta o desenvolvimento das ações socioeducativas no período contrário ao da escola. Sem essas atividades, corre-se o risco de o Programa permanecer na zona de atenção residual e de pouco efeito sobre a realidade que pretende modificar, inclusive sem o apoio das famílias. 
[...] dependendo da atividade que você oferece não é tão importante, não é porque a família não valoriza, é porque ela não conhece o valor, é diferente, ela não teve a oportunidade, então, não dá para dizer assim: "nossa, essas famílias não valorizam o que a gente oferece". Não! Elas não conhecem o valor, então, elas não têm como valorizar o desconhecido (Assistente Social do (REAS).

Durante as Oficinas, também foi reforçado que no dia a dia dos CRAS as assistentes sociais assumem diversas atividades, 0 que repercute na impossibilidade de efetuar planejamentos e avaliação dos vários projetos, programas e ações exercidas, o que poderia congregar estratégias de organização frente aos problemas atendidos, inclusive alterações objetivas que se fazem necessárias.

Outra dificuldade refere-se ao modus operandi das políticas sociais públicas, uma vez que se efetivam com um planejamento assimétrico e sempre de última hora.

[...] tudo chega em cima da hora, a gente tem prazo pra seguir. Esse Programa, por exemplo, que teve, o "de olho no futuro" [de informática], a gente tinha uma semana pra fazer contato com as famílias pra fazer a inscrição..., tem uma data de início.... Embora já tenha tido todas as conversas, até que o SENAC consegue aprovação com São Paulo..., mas o SENAC tem uma idade mínima que eles podem aceitar... Então tudo tem que ser acertado porque, no nosso caso, seriam 14 anos e tudo isso tem que ser conversado em São Paulo.... Então, quando bate o martelo e o curso vai iniciar a gente tem a data e tem o prazo e é tudo muito em cima da hora e tem que procurar as famílias, convencer... A grande dificuldade é que os nossos beneficiários já estão fora da escola... uma das exigências desse programa do SENAC é estar matriculado. Então, é uma série de coisas que a gente tem que fazer num curto espaço de tempo... é pressão, cobrança da Secretaria para seguir o prazo e não podemos parar as outras atividades, o acompanhamento das outras famílias (Psicóloga do CRAS-C).

A psicóloga informa a dificuldade que os profissionais enfrentam, devido às respostas que devem ser dadas em curto 
espaço de tempo, pois, como as atividades são descontínuas, quando ocorre a liberação de algum curso, o profissional tem que agir rapidamente para conseguir atender os quesitos de inclusão, conforme a instituição contratada. Ou seja, como o que estava sendo oferecido às famílias era um curso profissionalizante, comprado do SENAC, era necessário cumprir o prazo, bem como atender ao quesito da idade, diferente daquela considerada para o trabalho precoce. Outra questão é a exigência de certo nível de escolaridade. Para fazer o curso do SENAC, o aluno precisa saber ler e escrever "[...] a gente foi questionar junto à Secretaria porque mesmo quem está na $5^{a}$ série, não sabe nem ler, nem escrever, e a realidade que estamos vendo é essa, como que vai acompanhar?! Tem tudo isso. E alguns estão sem matrícula na escola" (Psicóloga do (RAS-C).

Quando se trata de crianças e mesmo adolescentes trabaIhadores, há o reconhecimento de que "[...] eles trabalham tanto que quando chegam na sala de aula eles querem dormir. Eles não têm condições de aprender [...]" (Assistente Social do CRAS-B).

O meu irmão tem 16 anos, estudava, daí o que aconteceu? Ele começou a trabaiar, aí ele parou de ir, daí ele fala, assim, que ficava muito cansado, que ele trabaiava durante o dia e ter que estudar de noite, daí ele acabou parando de estudar, aí os estudos dele foi assim, ele já perdeu o ano passado, ele perdeu um ano, aí, esse ano, ele vai perder de novo, né?, porque ele trabalha só que como ele fica muito cansado ele não vai pra escola, daí tipo assim, ele vai uma ou duas vezes na semana... eu acho que o trabalho interfere nos estudos, sim (Beneficiária do PETI, L, 14 anos de idade).

Observa-se que a adolescente explica que seu irmão de 16 anos de idade trabalhava durante o dia e estudava à noite. Ela delata as consequências, informando que ele já perdeu um ano de estudos e provavelmente perderia outro. A transferência dos estudos para o período noturno acompanha o trabalho precoce, quando não a sua desistência. O horário dos estudos é uma questão importante a ser considerada, tendo em vista que é muito mais difícil o aproveitamento ou rendimento escolar após um dia de trabalho. Além disso, diante das dificuldades do sistema de 
educação, não há um acompanhamento por parte da escola dos trabalhadores precoces, o que, somando-se aos efeitos da exploração da sua força de trabalho, favorece a evasão escolar.

A intersetorialidade entre as políticas sociais é fundamental, porém, no dia a dia dos serviços, é praticamente inexistente. As políticas de saúde, de assistência social e de educação precisam estreitar laços. A manutenção do menino e da menina na escola envolve a relação ensino-aprendizagem estabelecida entre o professor e o aluno e a escola e a comunidade. O PETI exige que o beneficiário esteja estudando, mas nem sempre a escola consegue ser para ele a porta para a formação e estimular o desejo pelos estudos. "Agora, o que a gente percebe é que a escola também não tem sido muito atrativa..." (Assistente Social do CREAS-C). Em muitas situações, a escola, que deveria ser o meio de retirar a criança e o adolescente de situações como o trabalho precoce, acaba não cumprindo esse papel. "A dificuldade de aprendizagem leva o menino bom da escola. Nós temos um menino que está na $5^{a}$ série, no $6^{a}$ ano, $5^{a}$ série agora, e que não sabe ler e escrever e esses casos dentro do PETI são bastante comuns" (Assistente Social do CREAS). A assistente social (CRAS-D) também referiu que "[...] Os alunos [...] veem a lousa tudo escrito e mal sabem o que se passa ali. Que motivação o aluno tem de fica dentro da sala [de aula]? Daí começa a bagunça [...] e, por outro lado, a serem perseguidos pelos professores, eles acabam saindo... e [...] eles têm que trabaIha, então uma coisa vai levando à outra".

O sucesso na escola não pode ser visto de modo isolado. As dificuldades intelectuais e a degradação da formação escolar não são "naturais", "neutras" ou dependentes unicamente do comportamento individual da criança e do adolescente. Esses são déficits que resultam das determinações econômicas, sociais, políticas e culturais a que as famílias estão sujeitas. O aproveitamento e o desempenho escolar estão atravessados, de ponta a ponta, pelos vários fatores presentes na vida cotidiana, a qual é perpassada pelos processos mais abrangentes determinados pelo nível de emprego e renda e pelo acesso às medidas de proteção social. Em poucas palavras, o sucesso da educação não depende apenas do dom individual ou da respectiva capacidade, mas plasma a organização social, econômica e política do país. 
Os pais beneficiários do PETI também revelaram as dificuldades dos filhos em relação à escola:

Ruim de escola, não sabe fazer conta até hoje (X. Pai beneficiário do PETI).

Esses dias eu fui na reunião da escola lá, a professora tava reclamando lá que... tem vez que ela até dorme lá na carteira, nossa senhora... (J. Pai beneficiário do PETI).

[...] os meninos de hoje, só fica na rua porque não têm um trabalho igual o curso, né?, igual de manhã vai na escola, à tarde no curso, mas tinha que ser assim, ó, todo dia ocupar o tempo da criança... o trabalho do PETI é um trabalho muito bom, só que eu acho que tinha que ser assim, mais contínuo na vida da criança ... (V. Mãe beneficiária do PETI).

O curso do SENAC pode ser excelente e necessário no atual contexto, mas as famílias beneficiárias do PETI estão num estágio de necessidade anterior à formação profissional. Elas necessitam de atividades socioeducativas mais simples e desenvolvidas no próprio bairro, que atendam às crianças e aos adolescentes no período contrário ao da escola. Essas atividades podem ter uma repercussão imediata no aprendizado, interesse e aproveitamento escolar: "Eles iam muito melhor na escola, não ficavam na rua aprendendo coisa que não presta. [...] e aprende coisa que não deve, vira ladrões... Lá não, lá ele aprendia a cantar, aprendia a se comunicar melhor, é, era mais educado, menos agressivo..." (F. Mãe beneficiária do PETI). "[...] bom, se tem atividade melhora tudo, porque assim ela não ficaria sozinha em casa e também não ficaria na rua, pois teria alguma coisa pra fazer" (T. Mãe beneficiária do $\mathrm{PETI}$ ).

\section{CONSIDERAÇÕES FINAIS}

Constatou-se que o baixo valor pago às bolsas, a raridade de projetos que ofereçam oportunidades para o acesso, a permanência escolar e o modus operandi das políticas sociais públicas configuram-se verdadeiros desafios para a efetivação do PETI. Esse Programa, apesar de representar algum avanço frente ao fenômeno do trabalho precoce, tem um efeito superficial frente à realidade que se propõe atender e modificar. 
Além das condições objetivas de precariedade que perpassam os serviços públicos, observou-se que nos CRAS não há uma equipe única responsável pelo $\mathrm{PETI}$, o atendimento a esse Programa é rotativo, o que se soma aos fatores já enunciados, corroborando a descontinuidade das ações. Além disso, a equipe multiprofissional precisa avançar para além do espontaneísmo e de ações individualizadas para alcançar estratégias balizadas em sínteses teóricas dos problemas atendidos e da atuação profissional. O trabalho mediado pela investigação e avaliação dos resultados e objetivos alcançados pode gerar um protagonismo importante tanto para o enfrentamento mais qualificado das demandas quanto para a realização profissional e reconhecimento do trabalho, o que talvez confronte com o sentimento de impotência.

A frustração e a impotência são sentimentos que se fazem presentes no exercício profissional do Serviço Social, sobretudo porque a sua ação acaba reduzida ao imediatismo e distante de resultados mais efetivos dos vários projetos e programas desenvolvidos, certamente, mediados por pequenas conquistas, mas que não logram a universalidade, tampouco a solução dos problemas, mesmo que focais, o que acaba, algumas vezes, reforçando-os.

Finalizando, sublinha-se que o caráter de fato inovador é o reconhecimento do trabalho abstrato como negativo ao desenvolvimento infantojuvenil, fruto de um processo histórico que, pela primeira vez no Brasil, adensou uma proposta para além da inserção no trabalho assalariado e que, portanto, se vincula à proteção integral. Contudo, a falta de tradição de políticas sociais universalizantes e desenvolvidas de modo intersetorial, acompanhada da falta de recursos e de reduzidas equipes profissionais, acaba restringindo a proteção social às crianças e aos adolescentes à condição de vulnerabilidade social das famílias. 


\section{REFERÊNCIAS}

ANDERSON, Perry. Balanço do neoliberalismo. In: SADER, Emir; GENTILI, Pablo. Pós-neoliberalismo: as políticas sociais e o Estado democrático. Rio de Janeiro: Paz e Terra, 1995. p. 9-23.

BIDARRA, Zelimar Soares; OLIVEIRA, Luciana Vargas Netto. Infância e Adolescência: o processo de reconhecimento e garantias fundamentais. Serviço Social e Sociedade, ano XXX, n. 94, p. 154-175, jun. 2008.

BRASIL. Disciplina a integração entre o Programa Bolsa Família e - Programa de Erradicação do Trabalho Infantil. Portaria n. 666, de 28 de dezembro de 2005. Diário Oficial da União (DOU). 251. ed. 2005 .

- Programa de Erradicação do Trabalho Infantil: cartiIha do PETI. Ministério do Desenvolvimento e Combate à Fome. Brasília, 2004.

GUERRA, Yolanda. A dimensão Investigativa do Serviço Social. In: CFESS/ABEPSS. Serviço Social: direitos sociais e competências profissionais. Conselho Federal do Serviço Social - CFESS; Associação Brasileira de Ensino e pesquisa em Serviço Social ABEPSS, v. 1. p. 701-717, 2009.

IAMAMOTO, Marilda Vilela. A Questão Social no Capitalismo. Temporalis - Revista da Associação Brasileira de Ensino e Pesquisa em Serviço Social, Brasília, v. 2, n. 3, p. 9-32, jan./jun. 2001.

LOURENÇO, Edvânia Ângela de Souza. PETI-COMPETI: uma análise intersetorial do trabalho infantil em Franca, SP. Relatório de Pesquisa e Extensão. Faculdade de Ciências Humanas e Sociais, Universidade Estadual Paulista, Franca. 2013. 81f. (Mimeo).

MARX, K.; ENGELS, Friedrich. O Manifesto Comunista. Rio de Janeiro: Paz e Terra, 2000. 
MOTA, A. E. Crise contemporânea e as transformações na produção capitalista. In Serviço Social: direitos sociais e competências profissionais. Brasília: Cfess/Abepss/UnB, 2009. Disponível em: $\quad$ http://cressmt.org.br/upload/arquivo/pos_graducao_ cfess_2010.pdf>. Acesso em: 9 nov. 2013.

OIT. Medir o progresso na Luta contra o Trabalho Infantil: estimativas e tendências mundiais 2000-2012. Bureau International do Trabalho; Programa Internacional para a Eliminação do Trabalho Infantil (IPEC) - Genebra: OIT, 2013. Disponível em: <http://www.ilo.org/wcmsp5/groups/public/---ed_norm/-- ipec/ documents/publication/wcms_221799.pdf> Acesso em: 21 jun. 2013.

OLIVEIRA, Tito Flavio Bellini Nogueira. Uma Nova Ofensiva do Capital? Impactos do Neoliberalismo e da Reestruturação Produtiva na Ação Sindical e no Setor Calçadista de Franca - SP. 2013. 26of. Tese (Doutorado em História) - Universidade Estadual Paulista, Franca, 2013.

PADILHA, Miriam Damasceno. Criança não deve trabalhar: a análise sobre o Programa de Erradicação do Trabalho Infantil e repercussão na sociabilidade das famílias participantes. Recife: Editora da UFPE, 2006.

SADER, Emir; GENTILI, Pablo. Pós-neoliberalismo: as políticas sociais e o Estado democrático. Rio de Janeiro: Paz e Terra, 1995.

SANT'ANA, Raquel Santos. Trabalhar é preciso, viver não é preciso: a desumanização do trabalho no corte de cana-de-açúcar e o Serviço Social. 2009. 230f. (Tese de Livre-docência)- Universidade Estadual Paulista, Franca, 2009.

SILVA, Jose Fernando Siqueira. Serviço Social: resistência e emancipação? São Paulo: Cortez, 2013.

SILVA, Maria Liduína de Oliveira. Adultização da Infância: o cotidiano das crianças trabalhadoras no mercado Ver-o-peso, em Belém do Pará. Serviço Social e Sociedade, São Paulo, ano 23, n. 69, p. 151-172, mar. 2002. 
- O Estatuto da Criança e do Adolescente e o Código de Menores: descontinuidades e continuidades. Serviço Social e Sociedade, São Paulo, n. 83, p. 30-48, set. 2005.

STICF, DIEESE, CUT. Trabalho infantil em Franca: crianças que estudam e trabalham. Campinas: Linhas gerais, 1995.

UNICEF. Infância e adolescência no Brasil. Disponível em: <http:// www.unicef.org/brazil/pt/activities.html>. Acesso em: 15 maio 2013. 